\title{
BMJ Open Prevalence and associated factors of depression among adolescent boys and girls in Bangladesh: findings from a nationwide survey
}

\author{
Malay Kanti Mridha (D) , ${ }^{1}$ Md Mokbul Hossain, ${ }^{1}$ Md Showkat Ali Khan, ${ }^{1}$ \\ Abu Abdullah Mohammad Hanif (D) , ${ }^{1}$ Mehedi Hasan (D) , ${ }^{1}$ Dipak Mitra, ${ }^{2}$ \\ Moyazzam Hossaine, ${ }^{1}$ Mohammad Aman Ullah, ${ }^{3}$ Samir Kanti Sarker, ${ }^{3}$ \\ S M Mustafizur Rahman, ${ }^{3}$ Md M Islam Bulbul, ${ }^{3}$ Abu Ahmed Shamim ${ }^{1}$
}

To cite: Mridha MK, Hossain MM, Khan MSA, et al. Prevalence and associated factors of depression among adolescent boys and girls in Bangladesh: findings from a nationwide survey. BMJ Open 2021;11:e038954. doi:10.1136/ bmjopen-2020-038954

- Prepublication history for this paper is available online. To view these files, please visit the journal online (http://dx.doi org/10.1136/bmjopen-2020038954).

Received 30 March 2020 Revised 07 December 2020 Accepted 02 January 2021

Check for updates

(c) Author(s) (or their employer(s)) 2021. Re-use permitted under CC BY-NC. No commercial re-use. See rights and permissions. Published by BMJ.

${ }^{1}$ Centre for Non-Communicable Diseases and Nutrition, BRAC James P Grant School of Public Health, BRAC University, Dhaka, Bangladesh

${ }^{2}$ Department of Public Health, North South University, Dhaka, Bangladesh

${ }^{3}$ National Nutrition Services (NNS), Directorate General of Health Services, Dhaka, Bangladesh

Correspondence to Malay Kanti Mridha; malay.mridha@bracu.ac.bd

\section{ABSTRACT}

Objective To assess the prevalence of and factors associated with depression among adolescent boys and girls.

Design We conducted a nationwide cross-sectional study. Setting This study was carried out in 82 randomly selected clusters (57 rural, 15 non-slum urban and 10 slums) from eight divisions of Bangladesh.

Participants We interviewed 4907 adolescent boys and 4949 adolescent girls.

Primary and secondary outcome measures The primary outcome measure was 'any depression' and the secondary outcome measures were types of depression: no or minimal, mild, moderate, moderately severe and severe.

Results The overall prevalence of no or minimal, mild, moderate, moderately severe and severe depression was $75.5 \%, 17.9 \%, 5,4 \%, 1.1 \%$ and $0.1 \%$, respectively. Across most of the sociodemographic, lifestyle and anthropometric strata, the prevalence of any depression was higher among adolescent girls. In both sexes, depression was associated with higher age, higher maternal education, paternal occupation e.g., business, absence of a 6-9-year-old member in the household, food insecurity, household consumption of unfortified oil, household use of non-iodised salt, insufficient physical activity (adjusted odds ratio, AOR: 1.24 for boys, 1.44 for girls) and increased television viewing time e.g., $\geq 121$ minute/day (AOR: 1.95 for boys, 1.99 for girls). Only among boys, depression was also associated with higher paternal education e.g., complete secondary and above (AOR: 1.42), absence of another adolescent member in the household (AOR: 1.34), household use of solid biomass fuel (AOR: 1.39), use of any tobacco products (AOR: 2.17), and consumption of processed food (AOR: 1.24). Only among girls, non-slum urban residence, Muslim religion, and household size $\leq 4$ were also associated with depression. Conclusion The prevalence of depression among adolescent boys and girls is high in Bangladesh. In most sociodemographic, lifestyle and anthropometric strata, the prevalence is higher among girls. In this age group, depression is associated with a number of sociodemographic and lyfestyle factors. The government
Strengths and limitations of this study

- To the best of our knowledge, this is the first paper reporting prevalence, sex-difference and associated factors of depression among the adolescent girls and boys using a nationally representative data set.

- Depression was measured through face-to-face interviews using the adolescent Patient Health Questionnaire.

- Data on sociodemographic and lifestyle factors were collected based on self-reports, which is prone to information bias.

- No data were collected on treatment-seeking practices of adolescents with depression.

- This cross-sectional study cannot establish causal association between depression and the factors examined.

of Bangladesh should consider these findings while integrating adolescent mental health in the existing and future programmes.

\section{INTRODUCTION}

Adolescence is the period when a human being transforms from childhood to adulthood. The WHO defines adolescents as persons from 10 through 19 years of age. ${ }^{1}$ As per the latest census carried out in Bangladesh, adolescents comprise more than one-fifth of the total population. ${ }^{2}$ During adolescence, every human being experiences physical, psychological and social changes. ${ }^{1}$ As these changes occur simultaneously and rapidly, adolescence is considered a period of vulnerability. ${ }^{1}$ Therefore, an adolescent can suffer from physical and mental health disorders, including depression.

Worldwide, depression is a common mental health disorder, and more than 264 million people are affected by it. Depression is also a 
major cause of disability and therefore, a major contributor to the global burden of disease. ${ }^{3}$ Depression can also be common among adolescents. ${ }^{4}$ In adolescents and young people, depression can increase the risk of poor health, suicide, unhealthy lifestyle behaviour ${ }^{5}$ and poor social well-being. ${ }^{6}$ There is also evidence that early life depression is related to lower educational attainment. ${ }^{7}$

Data from small studies revealed that there is a high prevalence of depression among adolescents in Bangladesh. For example, in a recent publication, Anjum et al reported that $36.6 \%$ of urban and semiurban adolescents in Bangladesh have depressive symptoms, and there is a higher prevalence of depression among the girls $(42.9 \%)$ than the boys $(25.7 \%) .{ }^{7}$ Authors of another recently published study reported that $19 \%$ of male and $30 \%$ of female school-going adolescents in Dhaka city suffer from depressive symptoms. ${ }^{5}$ However, as mentioned earlier, these studies were confined in small areas of Bangladesh and therefore, unable to report national estimates.

The government of Bangladesh developed a national strategy for adolescent health to prioritise activities to improve adolescent health during 2017-2030. One of the four strategic areas of this document is the mental health of adolescents. During the development of this strategy, the policymakers and programme managers in Bangladesh mentioned that there was a dearth of information on the prevalence of mental health problems among adolescents in Bangladesh. They also highlighted that lack of information posed a challenge for developing appropriate interventions to improve the mental health of adolescents. ${ }^{1}$ The United Nations Population Fund estimated that the proportion of adolescents in Bangladesh would continue to increase. ${ }^{8}$ Therefore, adolescents' health and adolescents' mental health are essential for attaining sustainable development goals in Bangladesh.

Given the lack of information about the mental health status of adolescents, we wanted to estimate the prevalence of depression among adolescent boys and girls in Bangladesh. We recently carried out a nationwide survey to understand the food security, nutrition and health status of six population groups (less than 5-year-old children, adolescent girls, adolescent boys, women aged 20-59 years, men aged 20-59 years and elderly persons). This survey was carried out as the 2018-2019 round of national nutrition surveillance. In this survey, we assessed depression along with nutritional status, non-communicable disease-related risk factors and dietary practices among the adolescents girls and boys. In this paper, we aimed to report the prevalence and associated factors of depression among adolescent girls and boys in Bangladesh.

\section{MATERIALS AND METHODS}

\section{Study design and setting}

This cross-sectional study was implemented between April 2018 and October 2019, and the data collection period was from 6 October 2018 to 31 October 2019. We enrolled participants from 82 randomly selected clusters
(57 rural, 15 non-slum urban and 10 slums) from all the divisions (Barisal, Chattogram, Dhaka, Khulna, Mymensingh, Rajshahi, Rangpur and Sylhet) and all types of residence (rural, non-slum urban and slums) of Bangladesh.

\section{Sampling}

We employed separate sampling techniques to select study subjects from rural and non-slums urban areas and slums. For the selection of rural clusters, two districts were randomly selected from each division in the first stage of the four-stage sampling. Afterwards, one subdistrict was randomly selected from each of the districts. In the third stage, we randomly selected 32 unions (two unions from each of the selected sub-district). Each selected union was divided into segments, with 250-400 households keeping the geographical demarcation of the villages uninterrupted. From the listed segments, we randomly picked two segments and these segments were our rural clusters. Accordingly, we selected 64 clusters from rural areas. However, due to administrative embargo and financial constraints, we could collect data from 57 rural clusters.

For the selection of the non-slum urban clusters, we randomly selected 16 wards (lowest administrative unit in the urban areas) from the eight administrative divisions. We then identified the mahallas in those wards. Ifthe mahalla had $>500$ households, we divided the mahalla into two or more segments so that each segment had 250-400 households within a demarcated geographical boundary. We randomly picked one from the listed mahalla/ segments as the non-slum urban cluster. We eventually found that one of these clusters overlapped with a slum cluster, but we did not arrange a replacement cluster. Therefore, we collected data from 15 urban clusters.

For the selection of slum clusters, we used data from the Census of Slum Areas and Floating Population $2014 .^{9}$ In the first stage, we identified slums with $\geq 300$ households. If there were $>500$ households in any slums, we divided the slum into two segments within demarcated geographical boundaries. Then, we randomly selected 10 slums cluster, each with $\geq 250-300$ households. We randomly selected one cluster from each division, except for Dhaka and Chattogram. As there are more slum population in Dhaka and Chattogram division, we selected two slum clusters from each of them.

We determined the sample size to generate estimates at the national, divisional and slum level. In case of adolescents and other population groups included in the survey, we noticed that the prevalence $(p)$ of key variables were between $4 \%$ and $98 \%$. Considering the probability of type I error, $\alpha=0.05$; margin of error, $d=0.05$ or $p / 2$ when $\mathrm{p} \leq 0.1$; design effect $=1.61$, we calculated that we needed 62 adolescent boys and 62 adolescent girls from each cluster. Therefore, the estimated sample size for adolescent girls and boys in the country was 11160 (5580 in each group). In reality, from the 82 completed clusters, we could collect data from 9856 adolescents. 


\section{Study procedures}

In each cluster, we listed all eligible participants in the households. Afterwards, we randomly selected the required number of study participants from each cluster with the condition that more than one eligible participant from one population group should not be selected. We listed 25371 households, 10529 adolescent boys and 10211 adolescent girls in the completed clusters and collected data from randomly selected 4907 adolescent boys and 4949 adolescent girls. Five data collection teams, each comprising one supervisor and four or five data collectors were deployed. The members of these teams were trained and standardised by the investigators and field coordinator of the study.

We collected data using face-to-face interviews and physical measurements after taking written informed consents. If the adolescents were less than 18 years old, informed written assents were taken, and informed written consent was taken from one of the parents or guardians. The data collectors entered data in tablet computers (Samsung Galaxy Tab A7) using a customised SurveyCTO application. They uploaded the data to the SurveyCTO server at the end of data collection everyday. Data collection questionnaires were pretested, and modifications were made. To ensure data quality, the data collection supervisors reinterviewed $5 \%$ of the study participants selected randomly within 48 hours of the initial visit by the data collectors. The data collection supervisors also observed the interviews of another $5 \%$ of the randomly selected participants.

\section{Outcome measures}

We used the nine-item adolescent Patient Health Questionnaire (PHQ-9) to measure the level of depression among both adolescent girls and boys. PHQ-9 has $89.5 \%$ sensitivity and $78.8 \%$ specificity for detecting depression among adolescents. Moreover, PHQ-9 has similar sensitivity and specificity when compared with other tools used in the primary healthcare settings, for example, Beck Depression Inventory and Short Mood and Feelings Questionnaires. PHQ-9 also has high reliability (Cronbach's $\alpha=0.83$ ) when used in Bangladeshi adolescents. $^{7}$

In the PHQ-9 questionnaire, study participants were asked how often they were bothered by nine specific symptoms related to depression over the last 2 weeks. Each symptom has four response options: not at all (score $=0$ ), several days (score $=1$ ), more than half of the days $($ score $=2$ ) and nearly every day $($ score $=3$ ). The scores of the individual study participants for all nine symptoms are added and then categorised into five levels of depression: none or minimal depression (score 0-4), mild depression (score 5-9), moderate depression (score 10-14), moderately severe depression (score 15-19) and severe depression (score 20-27). ${ }^{7}$ When the PHQ-9 score was between 5-27, the study particiapant was categorized as having 'any depression'.

\section{Other measures}

The household listing questionnaire included the numbers of children aged $0-5$ years, children aged 6-9 years, adolescents aged 10-19 years, women aged 20-59 years, men aged $20-59$ years and persons aged $\geq 60$ years along with other variables. The household questionnaire included questions on age, education, occupation of the household head, land ownership, livestock and asset ownership, household income, water, sanitation and hygiene practices, food security, and household use of salt, fuel and cooking oil. For measuring household food security, we used the Household Food Insecurity Access Scale questionnaire developed by the Food and Nutrition Technical Agency (FANTA). For collecting other household data, we used standard questions used by Measure Demographic and Health Surveys (Measure DHS) for Demographic Health Surveys. Measure DHS questions were also used to collect data on age, education, maternal and paternal education, maternal and paternal occupation, marital status from both adolescent girls and boys. From the adolescent girls, we collected additional data on reproductive history and menstrual hygiene. Women's Dietary Diversity Questionnaire was used to collect data on dietary practices of both adolescent girls and boys. ${ }^{10}$ We used WHO STEPS survey questions to collect data on lifestyle behaviour (use of tobacco products, physical activity and fruits and vegetable intake). ${ }^{11}$ Use of any tobacco product comprises consumption of smoked and/or smokeless tobacco products, insufficient physical activity was defined as having $<150$ minutes of moderateintensity physical activity or $<75$ minutes of vigorous intensity physical activity or equivalent during a typical week, and sufficient fruits and vegetables intake was defined as consumption of five or more servings of fruits and vegetables on an average day.

Concerning physical measurements, we measured the height of the adolescents using locally made stadiometers and weight using a weighing scale (Tanita UM070). All physical measurements were taken based on WHO guidelines, as specified in the Food and Nutrition Technical Assistance anthropometry manual. ${ }^{12}$ We took at least two measurements for each anthropometric indicator, and if the difference between two measurements was more than a prespecified limit $(0.1 \mathrm{~kg}$ for weight and $0.5 \mathrm{~cm}$ for height), we took a third measurement. We calculated Body Mass Index (BMI) using the WHO-recommended methods and categorised adolescents as underweight $\left(\mathrm{BMI}<18.5 \mathrm{~kg} / \mathrm{m}^{2}\right)$, normal (BMI: $\left.18.5-22.9 \mathrm{~kg} / \mathrm{m}^{2}\right)$ and overweight or obese $\left(\mathrm{BMI} \geq 23.0 \mathrm{~kg} / \mathrm{m}^{2}\right)$ using Asian cutoff for BMI. ${ }^{13}$

\section{Statistical analysis}

We used Stata V.15.0 (Stata Corp, College Station, TX, USA) to clean and analyse the data. We carried out descriptive analyses to report the background characteristics of the respondents. We constructed sampling weights, considering the selection probability of each participant in the final sample and used these weights to estimate 
the prevalence of different levels of depression for both adolescent boys and girls. We carried out analyses to test whether the prevalence of any depression significantly differs between the boys and girls across different sociodemographic, life-style and anthropometric strata. We performed bivariate logistic regression to explore the association between any depression and each of the explanatory variables identified based on literature review and available data. Finally, we carried out multivariable logistic regression taking the explanatory variables that had a $\mathrm{p}$ value $(\leq 0.2)$ in the bivariate analysis. If any of the explanatory variable is highly correlated (correlation coefficient of $\geq 0.5$ ) with another explanatory variable, we selected the variable that had the lowest $p$ value in the bivariate analysis. We also carried out regression diagnostics to verify whether the underlying assumptions of logistic regression were met.

\section{Ethics}

The data collectors administered informed written consent and assent (for 10-17-year-old adolescents) process as required. As part of the consenting process, each participant received information on the study, rights of the respondents, confidentiality and privacy procedures and her/his possible activities as a study participant. Each household received a small gift after completion of the data collection.

\section{RESULTS}

In this study, we analysed data from 9856 adolescents, and of them, 4907 (49.8\%) were boys, and 4949 (50.2\%) were girls. Fifty seven percent of boys and fifty four percent of girls were in their early adolescence, and about onethird of the adolescents were from urban areas (non-slum urban and slums). A higher proportion of adolescent girls than the boys (62\% vs $52 \%$ ) had some secondary education. Concerning the occupation of the mothers of the adolescents, more than $86 \%$ were homemakers; whereas, the occupations of the fathers of the adolescents had more variations. Eighty-seven per cent of the adolescents were Muslims; $49 \%$ lived in households that had at least another adolescent family member; about $12 \%$ of the adolescents lived in households with severe food insecurity (table 1).

We also found that about $5 \%$ and $1 \%$ of adolescent boys and girls, respectively, were current user of any tobacco products, $52 \%$ of boys and $55 \%$ of girls consumed inadequately diverse diet; $91 \%$ of boys and $94 \%$ of girls consumed less than five servings of fruits and vegetable per day; $81 \%$ of boys and $73 \%$ of girls consumed processed food in the last 24 hours; $33 \%$ of boys and $51 \%$ of girls did not perform at least 150 minutes of moderate-intensity physical activity or 75 minutes of vigorous physical activity or equivalent in a typical week; and $9 \%$ of boys and $10 \%$ of girls spent more than 2 hours/day for watching television (table 1). The height of $80 \%$ of girls and $38 \%$ of boys were between 140 and $160 \mathrm{~cm}$. The majority of the adolescents were underweight (64\% of boys and $52 \%$ of girls); $8 \%$ of boys and $12 \%$ of girls were overweight or obese. (table 1).

As shown in figure 1, the overall prevalence of depression was $24.5 \%$, and the prevalence of depression was higher among girls (27.0\%) than the boys (22.0\%). Among the depressed boys and girls, nearly three-fourths $(73 \%)$ were suffering from mild depression. The prevalence of moderate depression among girls and boys was $5.0 \%$ and $5.9 \%$, respectively. The prevalence of moderately severe and severe depression combined was $1 \%$ for boys and $1.4 \%$ for girls.

We further compared the prevalence of any depression (mild+moderate+moderately severe+severe) between boys and girls across different sociodemographic, lifestyle and anthropometric strata. In most cases, there was a statistically significant difference between the prevalence of any depression among girls and boys. In case of girls, the highest prevalence of depression was noticed among the consumers of tobacco products $(49.0 \%)$, and in case of boys, the highest prevalence of depression was noticed among the smokers $(46.0 \%)$. Adolescents living in severely food insecure households also had a high prevalence of depression (43.0\% among girls and 33.3\% among the boys) (table 2).

Multivariable logistic regression revealed that higher age, higher maternal education, higher paternal education, paternal occupation, absence of a 6-9-year-old member in the household, absence of another adolescent household member, food insecurity, household use of solid-biomass fuel, and tobacco consumption, household consumption of unfortified oil, household consumption of non-iodised salt, processed food intake, insufficient physical activity and higher television viewing time per day were associated with depression in adolescent boys. Compared with mothers and fathers with no education, adolescent boys having mothers and fathers with completed secondary or higher education had higher odds of depression (mothers: adjusted odds ratio (AOR): 1.57, 95\% CI: 1.13 to 2.19; fathers: AOR: 1.42, 95\% CI: 1.06 to 1.89). We also found that compared with adolescent boys living in food-secured households, adolescent boys living in the severe food-insecure households had higher odds of depression (AOR: 1.44, 95\% CI: 1.17 to 1.79 ). We also noticed a protective effect of mild food insecurity on depression (AOR: 0.63, 95\% CI: 0.52 to 0.76 ) among adolescent boys keeping the same reference group. Adolescent boys with insufficient physical activity (AOR: $1.24,95 \%$ CI: 1.06 to 1.46 ) and $\geq 121 \mathrm{~min} /$ day television viewing time (AOR: $1.95,95 \% \mathrm{CI}: 1.51$ to 2.51) had higher odds of depression compared with their counterparts performing sufficient physical activity and with $\leq 60 \mathrm{~min} /$ day television viewing time, respectively (table 3).

In case of adolescent girls, multivariable logistic regression revealed that age, non-slum urban residence, partial primary maternal education, paternal occupation, being Muslim, household size $\leq 4$, absence of a 
Table 1 Background characteristics of the study population by sex

Whole sample $(n=9856)$

Adolescent boy $(n=4907)$

Adolescent girl $(n=4949)$

$\begin{array}{llllll}\mathbf{n} & \% & \mathbf{n} & \mathrm{n} & \mathrm{n} & \%\end{array}$

\section{Sociodemographic characteristics}

Age

\begin{tabular}{|c|c|c|c|c|c|c|}
\hline $10-14$ & 5462 & 55.4 & 2789 & 56.8 & 2673 & 54 \\
\hline $15-17$ & 3062 & 31.1 & 1524 & 31.1 & 1538 & 31.1 \\
\hline $18-19$ & 1332 & 13.5 & 594 & 12.1 & 738 & 14.9 \\
\hline Rural & 6887 & 69.9 & 3438 & 70.1 & 3449 & 69.7 \\
\hline Non-slum urban & 1763 & 17.9 & 873 & 17.8 & 890 & 18 \\
\hline No education & 221 & 2.24 & 161 & 3.28 & 60 & 1.21 \\
\hline Partial primary & 2604 & 26.4 & 1518 & 30.9 & 1086 & 21.9 \\
\hline Complete primary & 1395 & 14.2 & 658 & 13.4 & 737 & 14.9 \\
\hline Partial secondary & 4357 & 44.2 & 1973 & 40.2 & 2384 & 48.2 \\
\hline Partial primary & 1270 & 12.9 & 633 & 12.9 & 637 & 12.9 \\
\hline Complete primary & 1721 & 17.5 & 844 & 17.2 & 877 & 17.7 \\
\hline Partial secondary & 2130 & 21.6 & 1081 & 22 & 1049 & 21.2 \\
\hline Complete secondary or above & 1021 & 10.4 & 514 & 10.5 & 507 & 10.2 \\
\hline \multicolumn{7}{|l|}{ Paternal education } \\
\hline No education & 4140 & 42 & 2026 & 41.3 & 2114 & 42.7 \\
\hline Partial primary & 1049 & 10.6 & 532 & 10.8 & 517 & 10.5 \\
\hline Complete primary & 1467 & 14.9 & 713 & 14.5 & 754 & 15.2 \\
\hline Partial secondary & 1699 & 17.2 & 875 & 17.8 & 824 & 16.7 \\
\hline Day labourer & 2418 & 24.6 & 1188 & 24.2 & 1230 & 24.9 \\
\hline Salaried staff & 1454 & 14.8 & 744 & 15.2 & 710 & 14.4 \\
\hline Business & 2268 & 23 & 1149 & 23.4 & 1119 & 22.6 \\
\hline Others & 2155 & 21.9 & 1049 & 21.4 & 1106 & 22.4 \\
\hline \multicolumn{7}{|l|}{ Marital status } \\
\hline Currently married & 725 & 7.36 & 43 & 0.88 & 682 & 13.8 \\
\hline Others & 9131 & 92.6 & 4864 & 99.1 & 4267 & 86.2 \\
\hline \multicolumn{7}{|l|}{ Religion } \\
\hline Muslim & 8611 & 87.4 & 4272 & 87.1 & 4339 & 87.7 \\
\hline Other & 1245 & 12.6 & 635 & 12.9 & 610 & 12.3 \\
\hline \multicolumn{7}{|l|}{ Household size } \\
\hline$\leq 4$ & 5352 & 54.3 & 2725 & 55.5 & 2627 & 53.1 \\
\hline$\geq 5$ & 4504 & 45.7 & 2182 & 44.5 & 2322 & 46.9 \\
\hline
\end{tabular}

Continued 
Table 1 Continued

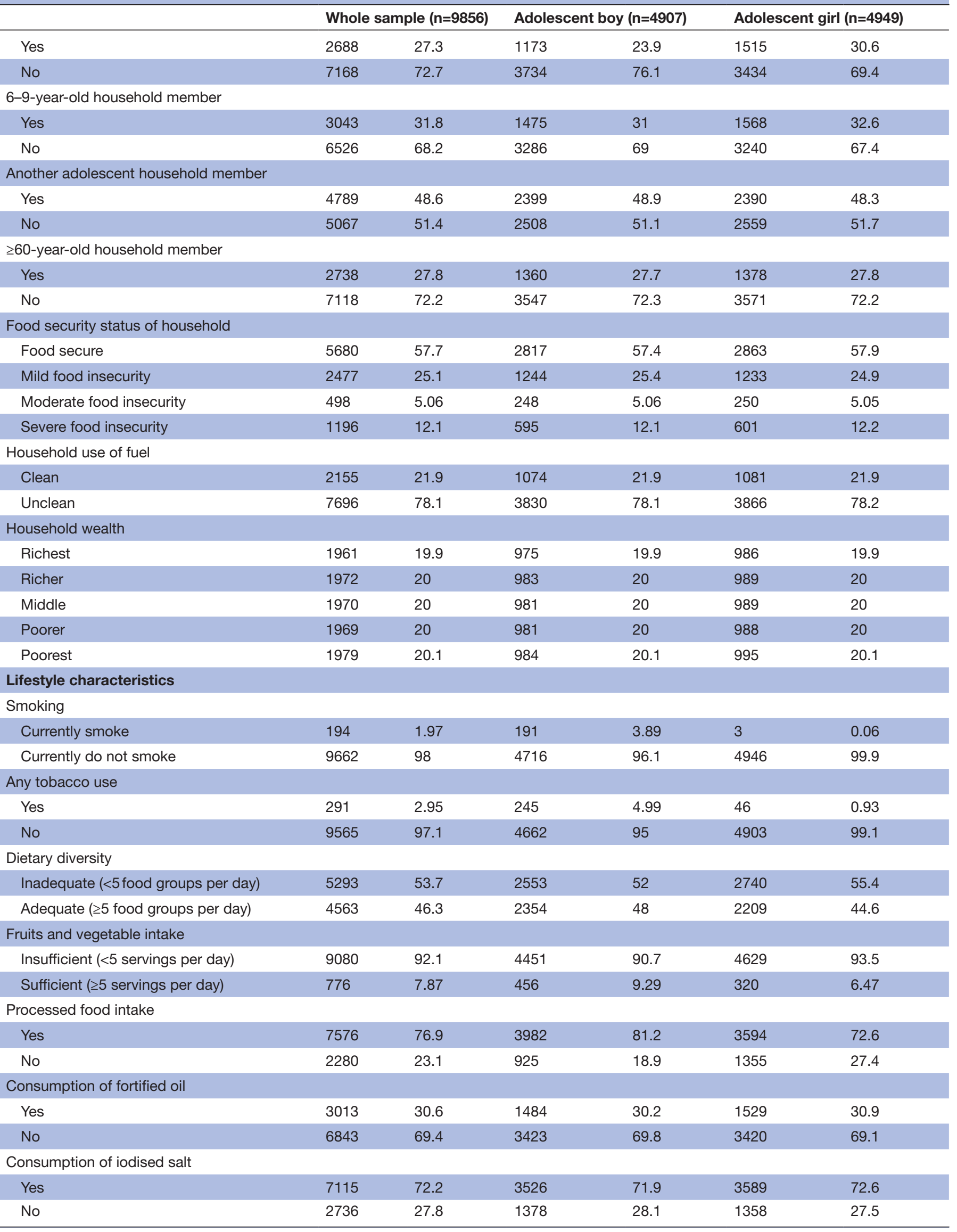


Table 1 Continued

\begin{tabular}{|c|c|c|c|c|c|c|}
\hline Physical activity & \multicolumn{2}{|c|}{ Whole sample $(n=9856)$} & \multicolumn{2}{|c|}{ Adolescent boy $(n=4907)$} & \multicolumn{2}{|c|}{ Adolescent girl $(n=4949)$} \\
\hline $\begin{array}{l}\text { Insufficient ( }<150 \text { minutes of moderate or } \\
<75 \text { minutes of vigorous physical activity or } \\
\text { equivalent/week) }\end{array}$ & 4128 & 41.9 & 1613 & 32.9 & 2515 & 50.8 \\
\hline $\begin{array}{l}\text { Sufficient ( } \geq 150 \text { minutes of moderate or } \\
\geq 75 \text { minutes of vigorous physical activity or } \\
\text { equivalent/week) }\end{array}$ & 5728 & 58.1 & 3294 & 67.1 & 2434 & 49.2 \\
\hline \multicolumn{7}{|l|}{ Sedentary time/day } \\
\hline$\leq 6$ hours & 4122 & 41.8 & 2141 & 43.6 & 1981 & 40 \\
\hline$>6$ hours & 5734 & 58.2 & 2766 & 56.4 & 2968 & 60 \\
\hline \multicolumn{7}{|l|}{ Television viewing time/day } \\
\hline None & 3520 & 35.7 & 1678 & 34.2 & 1842 & 37.2 \\
\hline$\leq 60$ minutes & 3519 & 35.7 & 1915 & 39 & 1604 & 32.4 \\
\hline $61-120$ minutes & 1883 & 19.1 & 896 & 18.3 & 987 & 19.9 \\
\hline$\geq 121$ minutes & 934 & 9.48 & 418 & 8.52 & 516 & 10.4 \\
\hline \multicolumn{7}{|l|}{ Anthropometric characteristics } \\
\hline \multicolumn{7}{|l|}{ Height } \\
\hline$<140 \mathrm{~cm}$ & 1780 & 18.1 & 1021 & 20.8 & 759 & 15.4 \\
\hline$\geq 140-<160 \mathrm{~cm}$ & 5814 & 59.1 & 1861 & 38 & 3953 & 80.1 \\
\hline$\geq 160 \mathrm{~cm}$ & 2243 & 22.8 & 2018 & 41.2 & 225 & 4.56 \\
\hline \multicolumn{7}{|l|}{ Weight } \\
\hline$<30 \mathrm{~kg}$ & 1602 & 16.3 & 949 & 19.4 & 653 & 13.2 \\
\hline$\leq 30-<50 \mathrm{~kg}$ & 5809 & 59 & 2446 & 49.9 & 3363 & 68 \\
\hline$\geq 50 \mathrm{~kg}$ & 2433 & 24.7 & 1505 & 30.7 & 928 & 18.8 \\
\hline \multicolumn{7}{|l|}{ Body Mass Index } \\
\hline Underweight & 5689 & 57.9 & 3110 & 63.5 & 2579 & 52.3 \\
\hline Normal & 3180 & 32.3 & 1405 & 28.7 & 1775 & 36 \\
\hline Overweight and obese & 965 & 9.81 & 383 & 7.82 & 582 & 11.8 \\
\hline
\end{tabular}

6-9-year-old member in the household, food insecurity, household consumption of unfortified oil, household consumption of non-iodised salt, insufficient physical activity and higher television viewing time were associated with depression. Compared with adolescent girls in the 10-14 years age group, adolescent girls between 14 and 17 years (AOR: $1.45,95 \%$ CI: 1.20 to 1.74 ) and 18-19 years (AOR: 1.92, 95\% CI: 1.51 to 2.45 ) of age

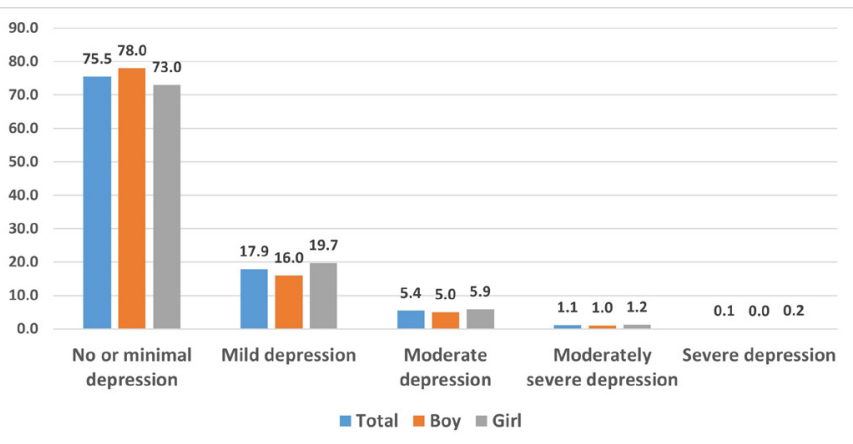

Figure 1 Prevalence of levels of depression among adolescent boys and girls. had higher odds of depression. Adolescent girls living in non-slum urban areas had higher odds of depression (AOR: $1.56,95 \%$ CI: 1.27 to 1.92 ) compared with adolescent girls living in rural areas. Compared with adolescent girls living in food secure households, adolescent girls living in severe food insecure households had higher odds of depression (AOR: 1.64, 95\% CI: 1.33 to 2.02). Like the adolescent boys, we noticed a protective effect of mild food insecurity on depression (AOR: 0.77, 95\% CI: 0.64 to 0.92 ) among adolescent girls keeping the same reference group. Household consumption of unfortified oil (AOR: 1.61, 95\% CI: 1.36 to 1.90 ) and household consumption of non-iodised salt (AOR: 1.81 95\% CI: 1.54 to 2.12 ) were associated with the higher odds of depression. Moreover, adolescent girls with insufficient physical activity (AOR: $1.44,95 \%$ CI: 1.25 to 1.67 ) and $\geq 121 \mathrm{~min} /$ day television viewing time (AOR: 1.99, 95\% CI: 1.59 to 2.49 ) had higher odds of depression compared with adolescent girls with performing sufficient physical activity and with $<60 \mathrm{~min} /$ day television viewing time, respectively (table 3 ). 
Table 2 Prevalence of any depression* among adolescent boys and girls by sociodemographic, lifestyle and anthropometric variables

\begin{tabular}{|c|c|c|c|c|}
\hline & $\begin{array}{l}\text { Whole sample }(\mathrm{n}=9569) \% \\
(95 \% \mathrm{Cl})\end{array}$ & $\begin{array}{l}\text { Adolescent boy }(n=4761) \% \\
(95 \% \mathrm{Cl})\end{array}$ & $\begin{array}{l}\text { Adolescent girl }(n=4808) \% \\
(95 \% \mathrm{Cl})\end{array}$ & $P$ value \\
\hline Overall & 24.52 (18.11 to 32.30$)$ & 22.02 (16.00 to 29.50$)$ & 27.01 (20.07 to 35.29$)$ & $<0.001$ \\
\hline \multicolumn{5}{|l|}{ Sociodemographic variables } \\
\hline \multicolumn{5}{|l|}{ Age } \\
\hline $10-14$ & 22.89 (16.31 to 31.14$)$ & 20.82 (14.51 to 28.94$)$ & 25.02 (18.00 to 33.64$)$ & 0.001 \\
\hline $15-17$ & 25.24 (18.95 to 32.77 ) & 23.05 (16.95 to 30.55 ) & 27.39 (20.33 to 35.81$)$ & 0.068 \\
\hline \multicolumn{5}{|l|}{ Place of residence } \\
\hline Rural & 24.71 (18.04 to 32.86$)$ & 22.28 (16.02 to 30.10$)$ & 27.14 (19.90 to 35.83 ) & $<0.001$ \\
\hline Non-slum urban & 20.51 (11.83 to 33.15$)$ & 15.19 (9.11 to 24.23$)$ & 25.30 (14.48 to 40.39$)$ & $<0.001$ \\
\hline Slum & 14.78 (4.29 to 40.16$)$ & 15.45 (3.83 to 45.61$)$ & 14.15 (4.72 to 35.44$)$ & 0.66 \\
\hline \multicolumn{5}{|l|}{ Educational status } \\
\hline Partial secondary & 24.50 (18.09 to 32.28 ) & 22.61 (16.37 to 30.37 ) & 26.02 (19.09 to 34.39$)$ & 0.089 \\
\hline Complete secondary or above & 30.74 (22.19 to 40.86$)$ & 25.12 (17.40 to 34.82$)$ & 36.07 (26.21 to 47.27$)$ & 0.002 \\
\hline \multicolumn{5}{|l|}{ Maternal education } \\
\hline No education & 25.22 (18.13 to 33.95$)$ & 21.85 (15.57 to 29.76 ) & 28.66 (20.51 to 38.47$)$ & $<0.001$ \\
\hline Partial primary & 25.63 (18.32 to 34.63$)$ & 24.70 (16.37 to 35.47$)$ & 26.62 (18.71 to 36.39$)$ & 0.661 \\
\hline Complete primary & 23.96 (18.38 to 30.59$)$ & 22.36 (16.39 to 29.73 ) & 25.46 (19.11 to 33.06$)$ & 0.321 \\
\hline Partial secondary & 22.15 (15.84 to 30.09 ) & 20.89 (14.08 to 29.85$)$ & 23.38 (16.96 to 31.32 ) & 0.313 \\
\hline Complete secondary or above & 27.35 (17.64 to 39.83 ) & 20.36 (11.41 to 33.68 ) & 33.83 (22.71 to 47.08$)$ & 0.008 \\
\hline \multicolumn{5}{|l|}{ Paternal education } \\
\hline No education & 26.45 (19.09 to 35.41$)$ & 23.59 (16.27 to 32.92) & 29.19 (21.53 to 38.25$)$ & 0.006 \\
\hline Other & 27.89 (20.46 to 36.78 ) & 26.56 (16.98 to 39.01 ) & 29.16 (21.30 to 38.51$)$ & 0.649 \\
\hline \multicolumn{5}{|l|}{ Paternal occupation } \\
\hline Farmer & 18.48 (13.93 to 24.10$)$ & 14.66 (10.94 to 19.37$)$ & 22.13 (15.78 to 30.13 ) & 0.011 \\
\hline Day labourer & 26.91 (18.98 to 36.65 ) & 26.22 (18.00 to 36.53 ) & 27.58 (19.61 to 37.28 ) & 0.509 \\
\hline Salaried staff & 21.53 (13.86 to 31.87 ) & 16.97 (10.06 to 27.20$)$ & 25.81 (17.04 to 37.07 ) & 0.006 \\
\hline Business & 25.97 (18.86 to 34.61$)$ & 23.26 (16.33 to 32.00$)$ & 28.75 (20.38 to 38.88 ) & 0.092 \\
\hline Others & 26.26 (19.06 to 34.99$)$ & 23.63 (16.67 to 32.36 ) & 28.98 (20.76 to 38.85 ) & 0.082 \\
\hline \multicolumn{5}{|l|}{ Religion } \\
\hline Muslim & 25.06 (18.37 to 33.20$)$ & 22.47 (16.17 to 30.32$)$ & 27.61 (20.36 to 36.27$)$ & $<0.001$ \\
\hline Other & 20.43 (12.35 to 31.89$)$ & 18.73 (10.35 to 31.52$)$ & 22.25 (13.88 to 33.69$)$ & 0.273 \\
\hline \multicolumn{5}{|l|}{ Household size } \\
\hline$\leq 4$ & 28.35 (20.65 to 37.56$)$ & 26.09 (18.57 to 35.33$)$ & 30.83 (22.84 to 40.16$)$ & $<0.001$ \\
\hline$\geq 5$ & 20.72 (15.48 to 27.15$)$ & 17.54 (13.01 to 23.23 ) & 23.57 (17.21 to 31.40$)$ & 0.005 \\
\hline \multicolumn{5}{|c|}{ Less than 5-year-old household member } \\
\hline Yes & 23.48 (17.53 to 30.71$)$ & 20.54 (15.04 to 27.40$)$ & 25.65 (18.99 to 33.67$)$ & 0.013 \\
\hline No & 24.89 (18.23 to 33.01$)$ & 22.44 (16.20 to 30.23 ) & 27.61 (20.25 to 36.42$)$ & 0.001 \\
\hline \multicolumn{5}{|l|}{ 6-10-year-old household member } \\
\hline Yes & 22.71 (16.32 to 30.69 ) & 20.49 (14.37 to 28.35$)$ & 24.7 (17.30 to 33.97$)$ & $<0.001$ \\
\hline
\end{tabular}


Table 2 Continued

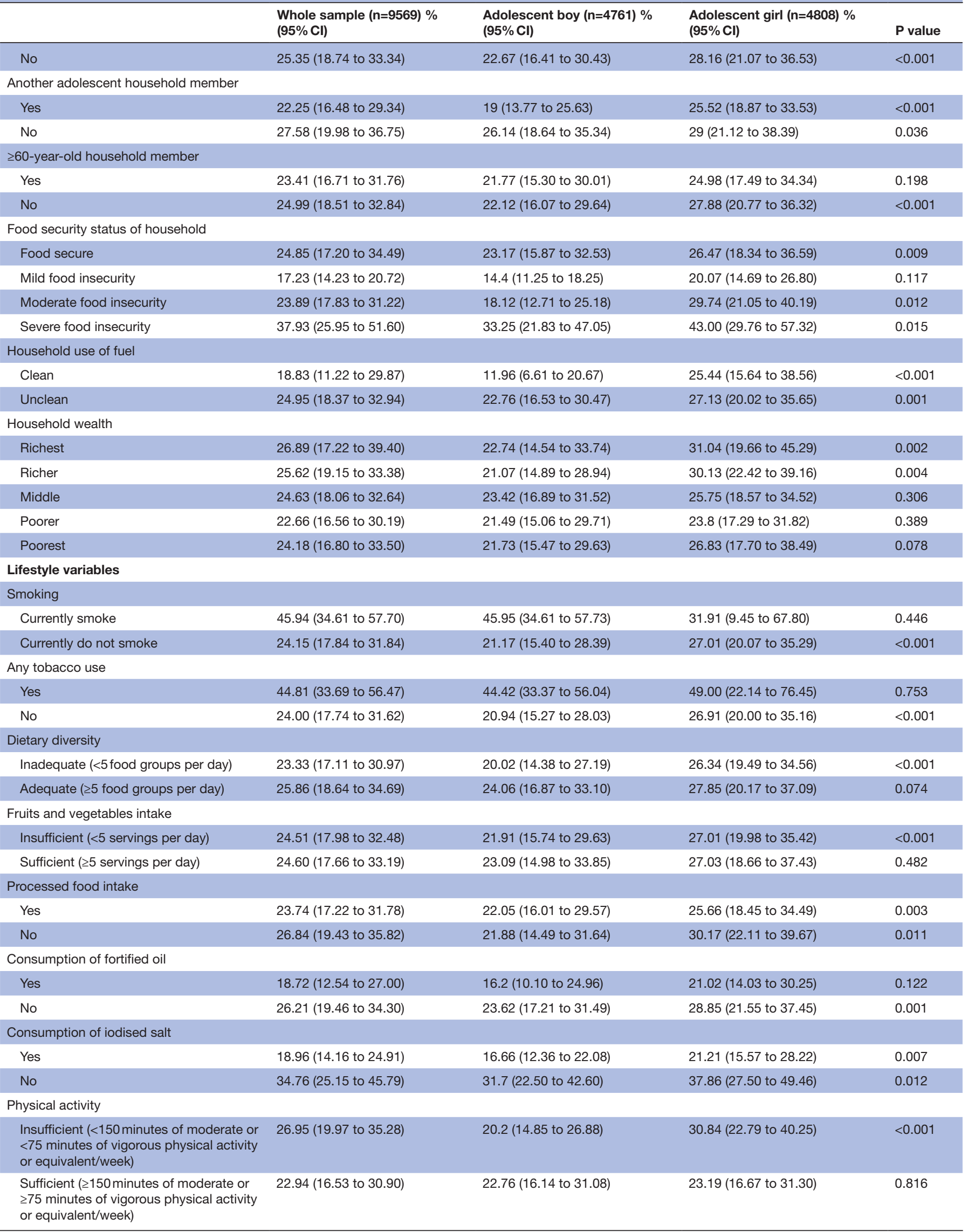


Table 2 Continued

\begin{tabular}{|c|c|c|c|c|}
\hline & $\begin{array}{l}\text { Whole sample }(n=9569) \% \\
(95 \% \text { Cl) }\end{array}$ & $\begin{array}{l}\text { Adolescent boy }(n=4761) \% \\
(95 \% \mathrm{Cl})\end{array}$ & $\begin{array}{l}\text { Adolescent girl }(\mathrm{n}=4808) \% \\
(95 \% \mathrm{Cl})\end{array}$ & $P$ value \\
\hline \multicolumn{5}{|l|}{ Sedentary time/day } \\
\hline$>6$ hours & 23.93 (17.90 to 31.22$)$ & 21.19 (15.51 to 28.26$)$ & 26.36 (19.64 to 34.39$)$ & 0.007 \\
\hline \multicolumn{5}{|l|}{ Television viewing time/day } \\
\hline None & 20.71 (15.76 to 26.72 ) & 18.11 (13.04 to 24.58$)$ & 23.18 (17.68 to 29.76 ) & 0.03 \\
\hline $61-120$ minutes & 25.81 (17.54 to 36.26$)$ & 21.07 (14.05 to 30.36$)$ & 30.1 (20.09 to 42.45$)$ & 0.005 \\
\hline$\geq 121$ minutes & 40.53 (28.53 to 53.78$)$ & 34.65 (21.14 to 51.20$)$ & 45 (33.20 to 57.40$)$ & 0.066 \\
\hline \multicolumn{5}{|l|}{ Anthropometric variables } \\
\hline \multicolumn{5}{|l|}{ Height } \\
\hline$<140 \mathrm{~cm}$ & 19.72 (13.60 to 27.72$)$ & 18.85 (13.10 to 26.35$)$ & 20.85 (13.62 to 30.57 ) & 0.428 \\
\hline$<30 \mathrm{~kg}$ & 21.89 (15.01 to 30.78$)$ & 19.89 (13.90 to 27.62$)$ & 24.61 (16.07 to 35.76$)$ & 0.057 \\
\hline$\leq 30-<50 \mathrm{~kg}$ & 25.52 (18.98 to 33.38 ) & 24.38 (17.79 to 32.46$)$ & 26.34 (19.56 to 34.48$)$ & 0.258 \\
\hline$\geq 50 \mathrm{~kg}$ & 24.03 (16.80 to 33.12$)$ & 19.4 (13.17 to 27.63$)$ & 32.51 (23.39 to 43.19 ) & $<0.001$ \\
\hline \multicolumn{5}{|l|}{ Body Mass Index } \\
\hline Underweight & 24.41 (17.86 to 32.42 ) & 22.94 (16.68 to 30.69 ) & 26.14 (18.98 to 34.85$)$ & 0.037 \\
\hline Normal & 23.89 (17.81 to 31.25$)$ & 20.28 (14.35 to 27.87 ) & 26.78 (20.18 to 34.60$)$ & 0.003 \\
\hline Overweight and obese & $28.17(19.10$ to 39.45$)$ & 20.54 (11.23 to 34.55$)$ & 32.86 (23.38 to 43.98$)$ & 0.022 \\
\hline
\end{tabular}

$P$ value was significant at $<0.05$.

*The cut-off of PHQ- 9 score $\geq 5$ was categorised as any depression for this analysis.

\section{DISCUSSION}

To the best of our knowledge, our study is the first in Bangladesh reporting the prevalence of and factors associated with depression using a nationally representative sample of both adolescent boys and girls. In our study, we found a high prevalence of depression in both boys and girls but compared with boys, adolescent girls had a higher level of depression across many sociodemographic, lifestyle and anthropometric strata. Our analysis revealed that depression was associated with higher age, higher maternal education, paternal occupation e.g., business, absence of a 6-9-year-old member in the household, food insecurity, household consumption of unfortified oil, household use of non-iodised salt, insufficient physical activity and high television viewing time among both boys and girls. Only among boys, depression was also associated with higher paternal education, absence of another adolescent member in the household, household use of solid biomass fuel, use of any tobacco products and consumption of processed foods. Only among girls, non-slum urban residence, Muslim religion and household size $\leq 4$ were also associated with depression.

Our findings about the prevalence of depression are consistent with a recently published study among adolescents in secondary schools. Though the study used Center for Epidemiological Studies Depression Scale (CESD-10), the authors of the study reported $25 \%$ overall prevalence of depression among the adolescents and a higher prevalence of depression among female adolescents $(30 \%$ in girls and $19 \%$ in boys). ${ }^{5}$ Another study using the PHQ-9 questionnaire among 13-17-year-old adolescents living in urban and semiurban Bangladesh revealed a higher prevalence of depression $(36.6 \%)$. However, as reported in our study, the authors of this study also reported a higher prevalence of depression among the girls $(42.9 \%)$ than the boys $(25.7 \%){ }^{7}$ The difference in reported prevalence between these two studies can be due to the inclusion of 10-19-year-old adolescents and also adolescents from rural, non-slum urban and slum areas in our study.

As revealed in our study, the association of depression with female gender and age is not an uncommon finding. Adolescent girls have more challenges during the transition from childhood to adulthood due to physical (e.g., development of secondary sex characteristics), psychological (e.g., socioemotional) and physiological (e.g., hormonal) changes. ${ }^{14}$ Moreover, cultural practices and gender norms in South-Asian societies may make girls more vulnerable to depression. ${ }^{15}$ For example, in South-Asian societies, adolescents cannot discuss their pubertal changes with their parents, and this may have an impact on their physical and emotional health ${ }^{5}$ leading to depression. Our findings concerning the higher prevalence of depression among adolescents in the higher age group are also consistent with results reported by other authors. ${ }^{516}$ There is a possibility that 
Table 3 Multivariable association of sociodemographic, lifestyle and anthropometric variables with any depression ${ }^{*}$ among adolescent boys and girls

\begin{tabular}{|c|c|c|c|c|c|c|c|c|}
\hline \multirow[b]{2}{*}{ Variables } & \multicolumn{4}{|c|}{ Adolescent boys $(n=4761)$} & \multicolumn{4}{|c|}{ Adolescent girls $(n=4808)$} \\
\hline & $\begin{array}{l}\text { Crude odds ratio } \\
\text { (COR) }(95 \% \mathrm{Cl})\end{array}$ & $P$ value & $\begin{array}{l}\text { Adjusted odds } \\
\text { ratio (COR) } \\
(95 \% \mathrm{Cl})\end{array}$ & $P$ value & $\begin{array}{l}\text { Crude odds ratio } \\
\text { (COR) }(95 \% \mathrm{Cl})\end{array}$ & $P$ value & $\begin{array}{l}\text { Adjusted odds ratio } \\
\text { (COR) }(95 \% \mathrm{Cl})\end{array}$ & $P$ value \\
\hline \multicolumn{9}{|l|}{ Age } \\
\hline $10-14$ & Ref & & & & Ref & & & \\
\hline $18-19$ & 1.25 (1.02 to 1.55$)$ & 0.035 & 1.44 (1.11 to 1.86$)$ & 0.006 & 1.89 (1.58 to 2.26$)$ & $<0.001$ & 1.92 (1.51 to 2.45$)$ & $<0.001$ \\
\hline \multicolumn{9}{|l|}{ Place of residence } \\
\hline Rural & Ref & & & & Ref & & & \\
\hline Non-slum urban & 1.10 (0.92 to 1.32$)$ & 0.275 & NA & NA & 1.69 (1.44 to 1.99$)$ & $<0.001$ & 1.56 (1.27 to 1.92$)$ & $<0.001$ \\
\hline Slum & 0.89 (0.72 to 1.11$)$ & 0.305 & NA & NA & 1.03 (0.84 to 1.26$)$ & 0.793 & 0.94 (0.75 to 1.18$)$ & 0.576 \\
\hline Complete primary & 0.96 (0.63 to 1.45$)$ & 0.831 & NA & NA & 0.7 (0.38 to 1.27$)$ & 0.238 & $0.83(0.44$ to 1.58$)$ & 0.577 \\
\hline Partial secondary & 0.95 (0.64 to 1.40$)$ & 0.797 & NA & NA & $0.92(0.52$ to 1.65$)$ & 0.786 & 0.97 (0.53 to 1.80$)$ & 0.931 \\
\hline $\begin{array}{l}\text { Complete } \\
\text { secondary or } \\
\text { above }\end{array}$ & 1.15 (0.76 to 1.76$)$ & 0.5 & NA & NA & 1.53 (0.85 to 2.77$)$ & 0.159 & 1.19 (0.63 to 2.26$)$ & 0.594 \\
\hline \multicolumn{9}{|l|}{ Maternal education } \\
\hline No education & Ref & & & & Ref & & & \\
\hline Partial primary & 1.37 (1.10 to 1.69$)$ & 0.004 & 1.34 (1.06 to 1.69$)$ & 0.015 & 1.35 (1.1 to 1.65$)$ & 0.004 & $1.42(1.14$ to 1.76$)$ & 0.002 \\
\hline Complete primary & 1.14 (0.93 to 1.40$)$ & 0.196 & 1.26 (1.01 to 1.57$)$ & 0.045 & 0.96 (0.8 to 1.17$)$ & 0.704 & 1.05 (0.85 to 1.29$)$ & 0.666 \\
\hline Partial secondary & 1.28 (1.07 to 1.54$)$ & 0.008 & 1.34 (1.08 to 1.67$)$ & 0.009 & 1.11 (0.93 to 1.32$)$ & 0.233 & 1.23 (0.99 to 1.52$)$ & 0.06 \\
\hline Partial secondary & 1.19 (0.98 to 1.44$)$ & 0.077 & 1.37 (1.09 to 1.71$)$ & 0.006 & 0.91 (0.75 to 1.1$)$ & 0.315 & 0.91 (0.73 to 1.13$)$ & 0.384 \\
\hline $\begin{array}{l}\text { Complete } \\
\text { secondary or } \\
\text { above }\end{array}$ & $1.12(0.92$ to 1.37$)$ & 0.259 & 1.42 (1.06 to 1.89$)$ & 0.019 & 1.27 (1.06 to 1.53$)$ & 0.011 & 1.15 (0.88 to 1.51$)$ & 0.319 \\
\hline \multicolumn{9}{|l|}{ Maternal occupation } \\
\hline Housewife & Ref & & & & Ref & & & \\
\hline Other & 0.96 (0.79 to 1.18$)$ & 0.698 & NA & NA & 0.99 (0.82 to 1.19$)$ & 0.884 & NA & NA \\
\hline \multicolumn{9}{|l|}{ Paternal occupation } \\
\hline Salaried staff & Ref & & & & Ref & & & \\
\hline Farmer & 0.82 (0.63 to 1.07$)$ & 0.142 & 1.46 (1.14 to 1.88$)$ & 0.003 & 0.89 (0.7 to 1.13$)$ & 0.351 & $1.04(0.79$ to 1.37$)$ & 0.773 \\
\hline Day labourer & 1.25 (0.99 to 1.57$)$ & 0.058 & $1.3(0.97$ to 1.75$)$ & 0.084 & 0.97 (0.78 to 1.21$)$ & 0.804 & 1.11 (0.86 to 1.42$)$ & 0.438 \\
\hline Business & 1.29 (1.03 to 1.62$)$ & 0.029 & 1.7 (1.32 to 2.19$)$ & $<0.001$ & 1.23 (0.99 to 1.52$)$ & 0.059 & 1.29 (1.03 to 1.63$)$ & 0.029 \\
\hline Others & 1.28 (1.02 to 1.62$)$ & 0.034 & 1.6 (1.24 to 2.06$)$ & $<0.001$ & 1.03 (0.83 to 1.28$)$ & 0.781 & $1.10(0.86$ to 1.41$)$ & 0.443 \\
\hline \multicolumn{9}{|l|}{ Religion } \\
\hline Muslim & 1.38 (1.20 to 1.59$)$ & $<0.001$ & 1.14 (0.97 to 1.34$)$ & 0.113 & 1.42 (1.25 to 1.61$)$ & $<0.001$ & 1.22 (1.04 to 1.45$)$ & 0.017 \\
\hline Other than Muslim & Ref & & & & Ref & & & \\
\hline \multicolumn{9}{|l|}{ Household size } \\
\hline$\leq 4$ & 1.38 (1.20 to 1.59$)$ & $<0.001$ & 1.14 (0.97 to 1.34$)$ & 0.119 & $1.42(1.25$ to 1.61$)$ & $<0.001$ & 1.22 (1.04 to 1.45$)$ & 0.017 \\
\hline
\end{tabular}


Table 3 Continued

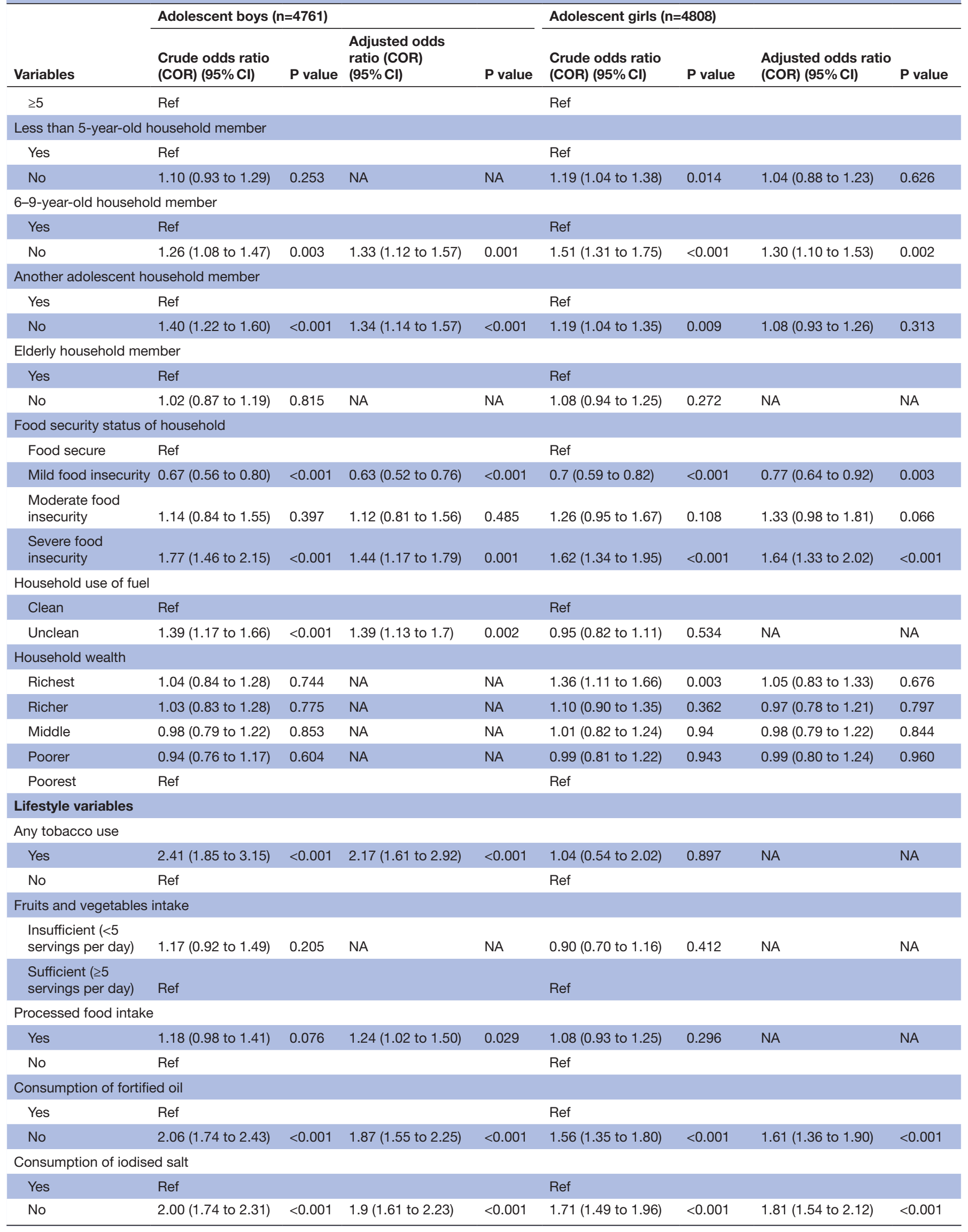


Table 3 Continued

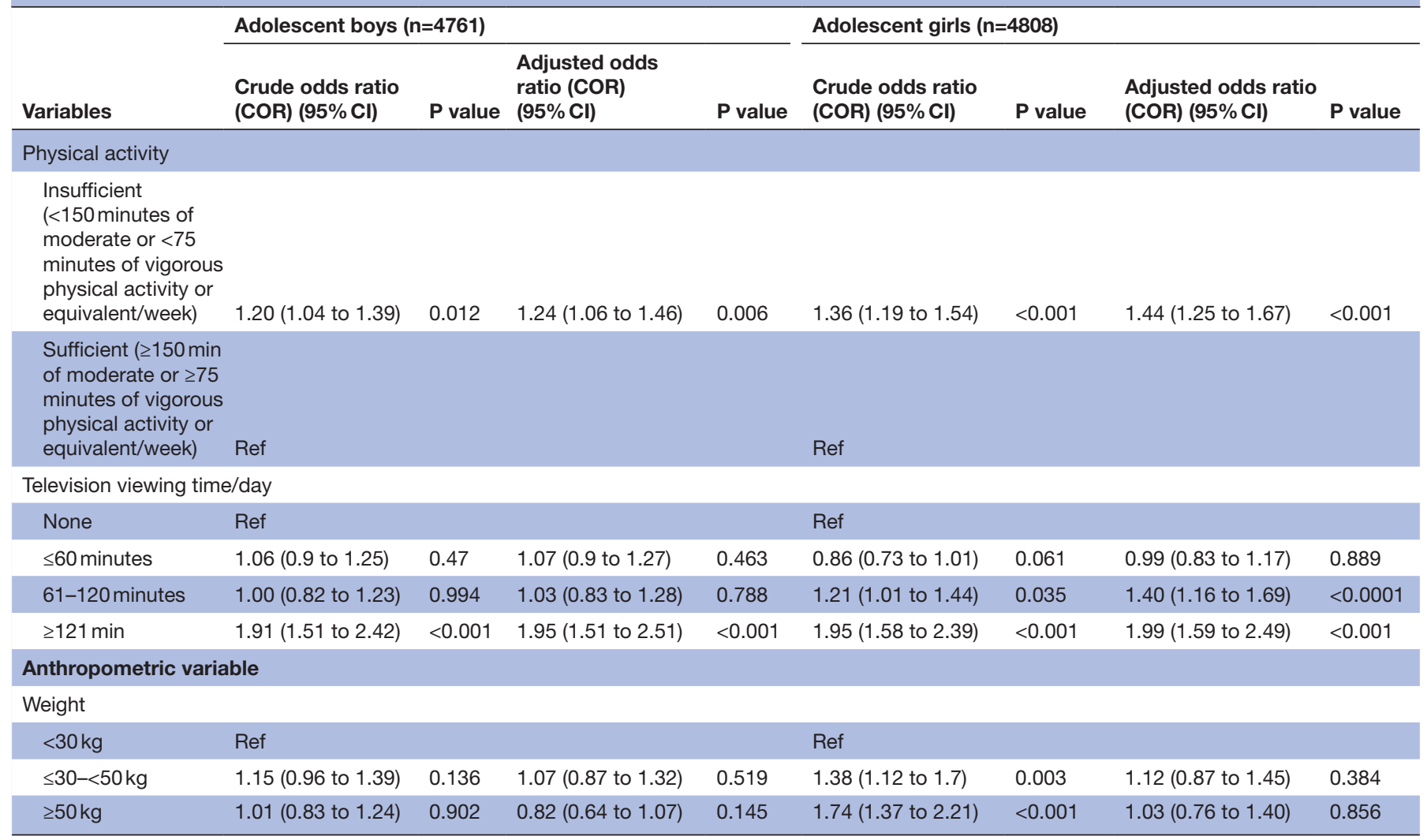

$P$ value was significant at $<0.05$.

${ }^{*}$ The cut-off of PHQ-9 score $\geq 5$ was categorised as any depression for this analysis.

older adolescents may face more factors and triggers of depression due to increased autonomy and social adjustment. ${ }^{17}$

As reported in our study, investigators from India observed an association of depression with higher maternal and paternal education among school-going adolescents. The authors of the Indian study described three possible reasons behind the association. The educated parents have high expectations from their children; they force their children towards more academic activities instead of recreational activities; and they do not find time to spend with the children as they are involved with jobs or outdoor activities. ${ }^{6}$ Investigators of a study in Pakistan described that parental bonding is crucial for the psychosocial functioning of any individuals. ${ }^{18}$ In Bangladesh, the higher odds of depression among adolescent boys and girls having mothers with partial primary education, and among adolescent boys having mothers and fathers with partial or completed secondary education or higher can also be due to the reasons mentioned above.

Though the association between Islam religion and higher odds of depression found in our study surprised us, authors from Pakistan revealed an opposite association, that is, adolescents from religious minorities (Christians and Hindus) are more depressed than their dominant counterpart (Muslims). ${ }^{19}$ A similar association was reported by an Indian study in which the dominant religion was Hindu. ${ }^{20}$ The investigators of the Pakistan study attributed the higher risk of depression among adolescents from religious minirities to a range of environmental and social conditions that prevailed due to marginalisation and oppression. As this is not the case for adolescent girls from the Muslim community in Bangladesh, there is a need for further research to find possible explanations behind this association found in our study.

The association between food insecurity and mental health disorders is also not uncommon. Investigators of a study implemented in the slums of India reported a strong association of food insecurity with depression (AOR: 13.96, 95\% CI: 5.89 to 31.79$){ }^{20}$ Researchers from Pakistan also reported an association between food insecurity and antepartum depression..$^{21}$ However, these studies did not report the odds of having depression by the level of food insecurity. In our case, we revealed that mild food insecurity was protective against depression, whereas, severe food insecurity increased the odds of depression among both boys and girls. There is evidence that food insecurity generates stress connected to the uncertainty regarding the maintenance of food supplies. ${ }^{22}$ Moreover, food insecurity can influence socioeconomic discrepancy and cultural sensitivity and can have a negative impact on mental health. ${ }^{23}$ The protective effect of mild food insecurity can be because of the fact that a mild form of the 
household problem may lead to an improved bonding between the members of a household, but further research is needed to ascertain this.

Researchers also investigated the association between the number of household members, presence of siblings and depression among the adolescents. We found that an absence of any 6-9-year-old members in the household (for both and girls) and an absence of at least another adolescent member in the household (for boys only) increased the odds of having depression. An Indian study reported a somewhat opposite association, that is, the presence of a sibling in the household increases the risk of depression and other selected mental health problems. ${ }^{20}$ However, the authors of a study carried out among the youths of Bangladesh reported that living with family and spending time with parents reduce both anxiety and depression. ${ }^{24}$ In our context, we think that the presence of another closed age member in the household may improve the sharing of life lessons, physical activity and thus lead to protection against depression.

Only among the boys, our analysis revealed that consumption of processed food was associated with an increased odds of depression and our findings are consistent with studies from Bangladesh and elsewhere. ${ }^{5} 25$ Bishwajit et al reported that consumption of fewer than five servings of fruits or vegetables increases the odds of depression in Nepal, India and Bangladesh..$^{25}$ Khan et al reported that consumption of sugary drinks increases the odds of depression. ${ }^{5}$ The authors of another recently published study implemented among Bangladeshi women in reproductive age group observed that consumption of Vitamin-A rich and Vitamin-C rich foods, eggs, dairy and fish are associated with lower odds of depression. ${ }^{26}$ We also observed that household use of unfortified oil and noniodised salt increased the odds of depression in both boys and girls. In Bangladesh, edible oil is fortified with vitamin A and or vitamin D. A study with the Japanese population reported that depressed individuals have a significantly low vitamin A level. ${ }^{27}$ The association between vitamin D deficiency and depression is also well established, ${ }^{28}{ }^{29}$ and there is evidence that vitamin D supplementation can ameliorate depression in adolescents. ${ }^{30}$ The relationship between poor mental health and iodine deficiency is also well known. ${ }^{31}$ Though Bangladesh is implementing a universal iodisation of salt programme for decades, the coverage of adequately iodised salt is still $69 \%$ in urban and $44 \%$ in rural areas. ${ }^{32}$ Our analysis suggests that salt iodisation may have the potential to improve the mental health of adolescents too.

Studies from Bangladesh ${ }^{733}$ also reported the association of insufficient physical activity and high screen time with depression among adolescents. In our study, we did not measure the total screen time that includes all screenbased activities. However, we found that both insufficient physical activity and television viewing time ( $\geq 121$ minute/ day for boys, and 61-120 minute and $\geq 121$ minute for girls) increased the odds of having depression. Studies reported that high screen time is associated not only with depression but also with anxiety, poor cognitive performance, behavioural problems, nervousness, sleep difficulties, attention deficit hyperactivity disorder, self-harm and social isolation among adolescents. ${ }^{34}{ }^{35}$ Physical activity can reduce depression and anxiety and enhance academic performance, self-esteem, quality of sleep and satisfaction in life. ${ }^{36}$ Given the fact that reduced screen time and recommended level of physical activity lower the odds of depression and other psychologic difficulties, ${ }^{35} 3839$ there is an urgent need of intervention to increase physical activity and decrease screen time among adolescents.

Among the boys, we also observed that depression was associated with household use of solid-biomass fuel and tobacco use. The use of solid-biomass fuel can be considered as a proxy indicator of air pollution. Associations between depression and tobacco use have also been reported by other authors, ${ }^{40}$ and there is evidence that smoking may enhance the effect of air pollution on depression. ${ }^{41}$ Smoking has been reported as a factor associated with mental health disorders either as a cause or a consequence. ${ }^{42}$ Due to the cross-sectional nature of this study, we cannot explain whether there is a reversecausality concerning tobacco consumption. Moreover, the association between non-slum urban residence and depression among adolescent girls is consistent with findings from other studies. ${ }^{43}$ The authors of a paper from Bangladesh also reported that people in semiurban areas have higher odds of depression than their rural counterparts. ${ }^{42}$

One of the strengths of the present study is that we included nationally representative samples of both adolescent girls and boys and the data were collected using face-to-face interviews. The large samples enabled us to run the statistical analyses separately for girls and boys y. However, the study had limitations. First, data on both outcome variable and many explanatory variableswere collected based on self-report, which is prone to information bias. Given that this component of the study was included in a large nationwide survey, all the known variables that are associated with depression among adolescents could not be included in the data collection tools. Second, as mentioned earlier, this cross-sectional study cannot establish causal association between depression and the factors examined. Third, we did not collect any data on treatment-seeking practices of adolescents with depression. Lack of data on the treatment-seeking practices bars us from giving a comprehensive overview of the situation of depression among adolescents in Bangladesh. Therefore, there is a need for further studies to find ways to integrate care of depression among adolescents in the health system.

In conclusion, we can say that our analysis revealed a high prevalence of depression among adolescents though the prevalence of moderately severe and severe depression was low. The prevalence of depression was higher among adolescent girls than the boys across many sociodemographic, lifestyle and anthropometric strata. We also identified some modifiable and non-modifiable 
factors associated with depression among the adolescents. The modifiable factors included food insecurity, household use of unfortified oil, household use of non-iodised salt, insuffcient physical activity, high television viewing time, household use of solid biomass fuel and use of any tobacco products. While the health and other relevant sectors can address these factors, the non-modifiable factors, for example, age, maternal education, paternal education, religion, absence of adolescent or 6-9-year-old household members, parental occupation can be used to develop screening tools for identifying adolescents at high risk of depression. Given the high prevalence of depression among both girls and boys, there is a need for integrating mental health interventions in primary healthcare and arranging counselling services in the educational institutions. Since the government of Bangladesh has already identified mental health as a priority to improve health of the adolescents, this paper is expected to fill some of the existing knowledge gaps and help the government of Bangladesh design and implement interventions for improving the mental health of adolescents.

\section{Twitter Abu Abdullah Mohammad Hanif @aamhanif}

Acknowledgements We are thankful to all the study participants, data collectors, data collection supervisors, members of the Technical Advisory Group and representatives of the national nutrition services other than the authors included in the paper.

Contributors MKM conceptualised the design of the study, led data collection, developed the statistical analysis plan, and drafted the initial manuscript. MdMH and AAMH managed data, carried out data analysis and reviewed the drafts of the manuscripts. MdSAK, MHa, DM, MHe, MAU, SKS, SMMR, MdMIB and AAS were involved in the conceptualisation and design of the study, supervision of data collection, as well as review and approval the final version of the manuscript. MKM was the principal investigator of the study and approved the final version of the manuscript.

Funding The study was funded by the National Nutrition Services (NNS), Directorate General of Health Services, Ministry of Health and Family Welfare, Government of Bangladesh (Memo: 45.165.032.01.00.003.2016-325; date: 10 December 2017).

Competing interests Some of the representatives of the Ministry of Health and Family Welfare, who approved the funding of the study were involved with the Technical Advisory Group. Though they had opinions about some maternal and child health and nutrition indicators, they did not have any role in the design, conduct, data analysis and manuscript writing of the adolescent component of the study.

Patient and public involvement Patients and/or the public were not involved in the design, or conduct, or reporting or dissemination plans of this research.

Patient consent for publication Not required.

Ethics approval The study obtained ethical approval from the Institutional Review Board (IRB) of the BRAC James P Grant School of Public Health, BRAC University, Dhaka, Bangladesh (IRB Reference no: IR-2018-20).

Provenance and peer review Not commissioned; externally peer reviewed.

Data availability statement Data will be available upon request. All such requests can be sent to IRB Chair, BRAC James P Grant School of Public Health, BRAC University, Dhaka, Bangladesh to the email address: irb-jpgsph@bracu.ac.bd.

Open access This is an open access article distributed in accordance with the Creative Commons Attribution Non Commercial (CC BY-NC 4.0) license, which permits others to distribute, remix, adapt, build upon this work non-commercially, and license their derivative works on different terms, provided the original work is properly cited, appropriate credit is given, any changes made indicated, and the use is non-commercial. See: http://creativecommons.org/licenses/by-nc/4.0/.

\section{ORCID iDs}

Malay Kanti Mridha http://orcid.org/0000-0001-9226-457X
Abu Abdullah Mohammad Hanif http://orcid.org/0000-0001-6274-5612 Mehedi Hasan http://orcid.org/0000-0003-2153-4979

\section{REFERENCES}

1 DGFP. National strategy for adolescent health 2017-2030. Dhaka Bangladesh: Directorate General of Family Planning, Ministry of Health and Family Welfare, 2016.

2 BBS. Population and housing census 2011: national report. Dhaka, Bangladesh: Bangladesh Bureau of Statistics, Statistics and Informatics Division, Ministry of Planning, 2015.

3 GBD 2017 Disease and Injury Incidence and Prevalence Collaborators. Global, regional, and national incidence, prevalence, and years lived with disability for 354 diseases and injuries for 195 countries and territories, 1990-2017: a systematic analysis for the global burden of disease study 2017. Lancet 2018;392:1789-858.

4 Venkataraman S, Patil R, Balasundaram S. Stigma toward mental illness among higher secondary school teachers in Puducherry, South India. J Family Med Prim Care 2019;8:1401-7.

5 Khan A, Ahmed R, Burton NW. Prevalence and correlates of depressive symptoms in secondary school children in Dhaka City, Bangladesh. Ethn Health 2020;25:34-46.

6 Shukla M, Ahmad S, Singh JV, et al. Factors associated with depression among school-going adolescent girls in a district of northern India: a cross-sectional study. Indian J Psychol Med 2019;41:46-53.

7 Anjum A, Hossain S, Sikder T. Investigating the prevalence of and factors associated with depressive symptoms among urban and semi-urban school adolescents in Bangladesh: a pilot study. Int Health 2019 doi:10.1093/inthealth/ihz092

8 BBS. Population projection of Bangladesh: dynamics and trends 2011-2061. Dhaka, Bangladesh: Bangladesh Bureau of Statisitcs, Statisitcs and Informatics Division, Ministry of Planning, 2015.

9 BBS. Census of slum areas and floating population 2014. Dhaka, Bangladesh: Bangladesh Bureau of Statistics, Statistics and Informatics Division. Ministry of Planning, 2015.

10 FAO. Minimum dietary diversity for women: a guide for measurement 360. Rome, Italy: Food and Agriculture Organization and Family Health International, 2016.

11 WHO. The WHO STEPwise approach to noncommunicable disease risk factor surveillance: who steps surveillance manual. Geneva, Switzerland: World Health Organization, 2017.

12 Cashin K, Oot L. Guide to anthropometry: a practical tool for program planners, managers, and implementers. 360. Washington, DC: Food and Nutrition Technical Assistance III Project (FANTA)/FHI, 2018.

13 WHO Expert Consultation. Appropriate body-mass index for Asian populations and its implications for policy and intervention strategies. Lancet 2004;363:157-63.

14 Angold A, Costello EJ, Worthman CM. Puberty and depression: the roles of age, pubertal status and pubertal timing. Psychol Med 1998;28:51-61.

15 Afzal S, Rana FT, Mehmood S. Determinants of depression in female adolescents and youth. Professional Med 2008;15:137-42.

16 Khalid A, Qadir F, Chan SWY, et al. Adolescents' mental health and well-being in developing countries: a cross-sectional survey from Pakistan. J Ment Health 2019;28:389-96.

17 Mohanraj R, Subbaiah K. Prevalence of depressive symptoms among urban adolescents in South India. J Indian Assoc Child Adolesc Ment Health 2010;6:33-43.

18 Khalid A, Qadir F, Chan SWY, et al. Parental bonding and adolescents' depressive and anxious symptoms in Pakistan. J Affect Disord 2018;228:60-7.

19 lqbal S, Ahmad R, Ayub N. Level of depression among adolescents of religious minorities and their dominant counterparts in Pakistan. $J$ Child Adolesc Ment Health 2012;24:163-71.

20 Rani D, Singh J, Acharya D, et al. Household food insecurity and mental health among teenage girls living in urban slums in Varanasi, India: a cross-sectional study. Int J Environ Res Public Health 2018;15 doi:10.3390/ijerph15081585

21 Ayyub H, Sarfraz M, Mir K, et al. Association of antenatal depression and household food insecurity among pregnant women: a Crosssectional study from slums of Lahore. J Ayub Med Coll Abbottabad 2018;30:366-71.

22 Whitaker RC, Phillips SM, Orzol SM. Food insecurity and the risks of depression and anxiety in mothers and behavior problems in their preschool-aged children. Pediatrics 2006;118:e859-68.

23 Weaver LJ, Hadley C. Moving beyond hunger and nutrition: a systematic review of the evidence linking food insecurity and mental health in developing countries. Ecol Food Nutr 2009;48:263-84. 
24 Arusha AR, Biswas RK. Prevalence of stress, anxiety and depression due to examination in Bangladeshi youths: a pilot study. Child Youth Serv Rev 2020;116:105254.

25 Bishwajit G, O'Leary DP, Ghosh S, et al. Association between depression and fruit and vegetable consumption among adults in South Asia. BMC Psychiatry 2017;17:15.

26 Sparling TM, Waid JL, Wendt AS, et al. Depression among women of reproductive age in rural Bangladesh is linked to food security, diets and nutrition. Public Health Nutr 2020;23:660-73.

27 Nguyen TTT, Tsujiguchi H, Kambayashi Y, et al. Relationship between vitamin intake and depressive symptoms in elderly Japanese individuals: differences with gender and body mass index. Nutrients 2017;9 doi:10.3390/nu9121319

28 Anglin RES, Samaan Z, Walter SD, et al. Vitamin D deficiency and depression in adults: systematic review and meta-analysis. $\mathrm{Br} \mathrm{J}$ Psychiatry 2013;202:100-7.

29 Spedding S. Vitamin D and depression: a systematic review and meta-analysis comparing studies with and without biological flaws. Nutrients 2014;6:1501-18.

30 Högberg G, Gustafsson SA, Hällström T, et al. Depressed adolescents in a case-series were low in vitamin $\mathrm{D}$ and depression was ameliorated by vitamin D supplementation. Acta Paediatr 2012;101:779-83.

31 Vargas-Uricoechea H, Pinzón-Fernández MV, Bastidas-Sánchez $\mathrm{BE}$, et al. lodine status in the Colombian population and the impact of universal salt iodization: a double-edged sword? J Nutr Metab 2019;2019:6239243

32 Knowles JM, Garrett GS, Gorstein J, et al. Household coverage with adequately iodized salt varies greatly between countries and by residence type and socioeconomic status within countries: results from 10 national coverage surveys. J Nutr 2017;147:1004S-14.

33 Khan A, Uddin R, Burton NW. Insufficient physical activity in combination with high screen time is associated with adolescents' psychosocial difficulties. Int Health 2018;10:246-51.
34 Page AS, Cooper AR, Griew P, et al. Children's screen viewing is related to psychological difficulties irrespective of physical activity. Pediatrics 2010;126:e1011-7.

35 Hamer M, Stamatakis E, Mishra G. Psychological distress, television viewing, and physical activity in children aged 4 to 12 years. Pediatrics 2009;123:1263-8.

36 Sund AM, Larsson B, Wichstrøm L. Role of physical and sedentary activities in the development of depressive symptoms in early adolescence. Soc Psychiatry Psychiatr Epidemiol 2011;46:431-41.

37 White K, Kendrick T, Yardley L. Change in self-esteem, self-efficacy and the mood dimensions of depression as potential mediators of the physical activity and depression relationship: exploring the temporal relation of change. Ment Health Phys Act 2009;2:44-52.

38 Bell SL, Audrey S, Gunnell D, et al. The relationship between physical activity, mental wellbeing and symptoms of mental health disorder in adolescents: a cohort study. Int $J$ Behav Nutr Phys Act 2019;16:138

39 Matin N, Kelishadi R, Heshmat R, et al. Joint association of screen time and physical activity on self-rated health and life satisfaction in children and adolescents: the CASPIAN-IV study. Int Health 2017:9:58-68.

40 Shaikh BM, Doke PP, Gothankar JS. Depression, anxiety, stress, and stressors among rural adolescents studying in Pune and a rural block of Nanded district of Maharashtra, India. Indian J Public Health 2018;62:311-4.

41 Lin H, Guo Y, Kowal P, et al. Exposure to air pollution and tobacco smoking and their combined effects on depression in six low- and middle-income countries. Br J Psychiatry 2017;211:157-62.

42 Islam FMA. Psychological distress and its association with sociodemographic factors in a rural district in Bangladesh: a crosssectional study. PLoS One 2019;14:e0212765.

43 Li G, Mei J, You J, et al. Sociodemographic characteristics associated with adolescent depression in urban and rural areas of Hubei Province: a cross-sectional analysis. BMC Psychiatry 2019;19:386. 